Fredo Schotanus

University of Twente

Helen Walker

University of Warwick
Elmer Bakker

Improvement and Efficiency South East

Michael Essig

Bundeswehr University Munich

\title{
Development of Purchasing Groups during Their Life Cycle: From Infancy to Maturity
}

Increasingly, public sector organizations collaborate to buy products and services. They collectively form purchasing groups to deliver more value for money. What is the progress of these small-scale developments of public sector purchasing groups to date, in the early phases of their life cycle? Although previous research provides general descriptions of life-cycle phases, little attention has been paid to detailed small-scale developments that take place within each life-cycle phase. As a result, little knowledge is available about small-scale developments of purchasing groups. More insight is important in order to better understand how purchasing groups can develop over time from one life-cycle phase into another. Three in-depth case studies from different countries offer a unique comparative overview of smallscale developments in these early life-cycle phases for their five dimensions. Most small-scale problems follow a predictable path, but the way in which the purchasing groups deal with such problems differs depending on the specific situation of the group.

$\mathrm{T}$ here is evidence that governments all over the world are encouraging public sector organizations to collaborate when they buy products and services in order to achieve economies of scope and scale. For example, in the United Kingdom, a government strategy highlighted deriving value for money through collaborative purchasing (Bevir and O'Brien 2001; Communities and Local Government 2008; HM Treasury 2007; NAO and Audit Commission 2010). In the Netherlands, the government is actively encouraging collaborative purchasing (PIANOo 2007). In Germany, the federal government started initiatives (the Seven-Points Program on Public Procurement and the Program on Advanced Administration through Innovation) that give strategic directions for public supply, including suggestions to bundle demand.
More examples of collaborative contracts becoming increasingly popular can be found in countries such as the United States and Australia (Australia Department of Finance and Deregulation 2008; NASPO 2008).

While there is evidence of collaborative purchasing policies in different countries, there is a gap between policy goals and the realities of public sector organizations in purchasing groups. Some groups form and collaborate successfully, but some fail or dismantle, particularly in the early stages (Schotanus and Telgen 2007). This paper explores what happens in the early stages of purchasing groups, aiming to provide insights to assist the development of more successful collaboration in purchasing groups. We define these purchasing groups as organizations in which collaborative purchasing processes take place. Collaborative purchasing is then defined as the collaboration between multiple organizations in one or more steps of the purchasing process by pooling or sharing purchasing volumes, information, and/ or resources. By pooling or sharing, the collaborating organizations can obtain lower prices, reduce transaction costs, exchange knowledge and share lessons learned, and increase the quality of purchasing processes as well as the quality of purchased products and services. Although there seem to be some clear benefits from collaborating for public sector performance, relatively young purchasing groups still struggle with development (Schotanus and Telgen 2007).

In the field of public administration, some research has been conducted on the large-scale development of purchasing groups. For example, D'Aunno and Zuckerman (1987), Johnson (1999), and Nollet and Beaulieu (2003) made important contributions in this area (Bakker et al. 2008). These three papers
Spotlight on Critical Grassroots Public Administration Issues

Fredo Schotanus is a part-time assistan professor of purchasing management and management science at the University of Twente in the Netherlands. In addition to his academic activities, he works as a consultant at Significant. He has published a book and several articles and book chapters on subjects in purchasing management. His research interests include public management, group purchasing, purchasing and supply management, allocation problems, and supplier selection.

E-mail: f.schotanus@utwente.nl

Elmer Bakker is a procurement development manager with Improvement and Efficiency South East in the United Kingdom. In a previous role, he was a research officer at the Centre for Research in Strategic Purchasing and Supply, University of Bath School of Management. His research interests include public procurement, procurement strategy, collaboration, supplier relationship management and the professionalization of the purchasing and supply profession in general.

E-mail: elmer.bakker@southeastiep.gov.uk

Helen Walker is an associate professor in purchasing and supply management at Warwick Business School, University of Warwick in the United Kingdom. Her research interests include investigating sustainable procurement in the public and private sectors. She is also a visiting professor in the W. P. Carey Business School at Arizona State University.

E-mail: helen.walker@wbs.ac.uk

Michael Essig is a professor in materials management and distribution at Bundeswehr University Munich in Germany and codirects the Research Center for Law and Management of Public Procurement as well as the Transfer Center for Defense Supply Chain Management. His research interests include strategic procurement, public procurement, and supply chain management. He teaches in several international supply management programs, including the University of San Diego, the University of St. Gallen, and the University of Grenoble.

E-mail: michael.essig@unibw.de 
describe the main life-cycle phases of purchasing groups (i.e., largescale developments). Unfortunately, little is known about detailed developments within each life-cycle phase (i.e., small-scale developments). These detailed small-scale developments in organizations are different from the long-term transition from one life-cycle phase to another (Smith, Carroll, and Ashford 1995). This means there is little evidence on when and under what circumstances specific problems can be expected, prevented, or overcome in purchasing groups within each life-cycle phase. We assume that such problems within a phase can cause development to stagnate and could cause termination, which is especially relevant in the early phases when these purchasing groups are least mature and most vulnerable. Insight into small-scale developments could improve our understanding on how purchasing groups develop over time and support relatively young purchasing groups in their performance and development.

To bridge the aforementioned research gap and to create a better understanding of developments within life-cycle phases, this paper explores small-scale developments in life-cycle phases. Our research question is as follows: what are the small-scale developments that take place in the early life-cycle phases of purchasing groups? To capture these developments in early life-cycle phases, we have chosen to focus on three relatively recently established purchasing groups in different countries.

This paper makes a novel contribution in three ways. First, our study extends beyond the existing literature by looking at a more detailed level at developments within life-cycle phases. Interestingly, we find that the small-scale developments in the three cases studies are similar. Second, our research provides insights for public sector practitioners seeking to collaborate with other organizations on procurement. Third, our research aims to inform policy makers, who are keen to promote collaborative purchasing, to focus on supporting the developments.

The paper is organized in the following way. First, we review the existing literature on purchasing group development. Next, we describe the three case studies and the methodology used. In the results section, we aim to identify small-scale developments. The last sections discuss the implications, limitations, and conclusions.

\section{Literature Review}

In this section, we first discuss the existing literature on life-cycle phases. Next, we discuss the relevance of studying small-scale developments in more detail.

\section{A Life-Cycle Model of Purchasing Groups}

When purchasing groups develop over time, they should be organized differently and should be applicable to the accomplishment of different tasks, goals, and strategies (based on Thompson et al.
1991). In the literature, three life-cycle models are discussed in the context of collaborative purchasing that describe how a purchasing group develops over time (D'Aunno and Zuckerman 1987; Johnson 1999; Nollet and Beaulieu 2003). The core theoretical assertion of the life-cycle models is that purchasing groups pass through predictable life-cycle phases. A number of typical developments are expected to occur as young, small, and simple purchasing groups become older, larger, and more complex (based on Miller and Friesen 1984).

The three life-cycle models were developed independently from one another, but overlap substantially. For instance, all models recognize four similar life-cycle phases and that purchasing groups develop in dimensions such as size. We have integrated the three models into one life-cycle model (see table 1). Note that we distinguish between early life-cycle phases and mature phases. The early phases are typically relevant for relatively young purchasing groups, which are quite common in the public sector (Schotanus 2007).

The labels of the four life-cycle phases in the table are based on the results of D'Aunno and Zuckerman (1987). The labels of the seven dimensions in the table are based on the dimensions of organizational types developed by Mintzberg $(1979,1983)$ and on the interorganizational dimensions developed by Miller and Friesen (1984) and Nollet and Beaulieu (2003).
This paper makes a novel contribution in three ways. First, our study extends beyond the existing literature by looking at a more detailed level at developments within life-cycle phases. ... Second, our research provides insights for public sector practitioners seeking to collaborate with other organizations on procurement. Third, our research aims to inform policy makers, who are keen

to promote collaborative purchasing, to focus on supporting the developments.
Although the message of life-cycle models is that, in general, purchasing groups tend to follow the lifecycle pattern, Nollet and Beaulieu (2003) note that a purchasing group does not always have to start in the first life-cycle phase, nor must the final phase be aimed at as a key objective. In addition, based on contingency theory (e.g., Woodward 1958, 1965), we note that more developed forms do not always have to be the best forms, as different organizational forms are appropriate in different circumstances. We also acknowledge that life-cycle phases can only be assessed retrospectively, and the boundaries between phases are not clear-cut. Nevertheless, they are a useful concept to describe what happens over time and to learn from it (Greiner 1972).

\section{Small-Scale Developments of Public Sector Purchasing Groups}

Table 1 is a useful model on a high level, but it does not specify in detail how purchasing groups develop in a life-cycle phase. This is lamentable, as life-cycle phases may last for several years, and during these years, several small-scale developments may take place. For instance, a purchasing group in the first life-cycle phase typically encounters several problems (and small-scale developments) because of limited resources, and a group in the third phase typically encounters several problems because of a growing number of members. A model that describes typical small-scale developments of purchasing groups could fill in this void. Unfortunately, although collaboration has been explored intensively in the literature (e.g., Leach 2006), the literature does not provide a model that describes small-scale developments taking place in life-cycle phases. 


\begin{tabular}{|c|c|c|c|c|}
\hline \multirow[t]{2}{*}{ Dimensions } & \multicolumn{2}{|l|}{ Early Life-Cycle Phases } & \multicolumn{2}{|l|}{ Mature Life-Cycle Phases } \\
\hline & 1. Informal coalition emergence & $\begin{array}{l}\text { 2. Formal collaborative } \\
\text { transition }\end{array}$ & 3. Collaborative maturity & 4. Cross-road \\
\hline Age and size & $\begin{array}{l}\text { Small; local; usually few members; } \\
\text { young }\end{array}$ & Medium; relatively young & $\begin{array}{l}\text { Medium to large; regional; may have many } \\
\text { members; relatively old }\end{array}$ & \multirow{7}{*}{$\begin{array}{l}\text { On the one hand, central deci- } \\
\text { sion making may increase, } \\
\text { what enables the group to } \\
\text { further expand; on the other } \\
\text { hand, members may withdraw } \\
\text { as the group reduces the } \\
\text { autonomy of the members }\end{array}$} \\
\hline $\begin{array}{l}\text { Member rela- } \\
\text { tionships }\end{array}$ & $\begin{array}{l}\text { Low-involvement relationships between } \\
\text { members; members share similar } \\
\text { ideologies and dependencies }\end{array}$ & $\begin{array}{l}\text { Relationships between } \\
\text { members become closer }\end{array}$ & $\begin{array}{l}\text { Group becomes more capable in addressing } \\
\text { member concerns equitably and sustains } \\
\text { member commitment }\end{array}$ & \\
\hline Goals & $\begin{array}{l}\text { Lobby and find fields to collaborate; } \\
\text { basic benefits; external changes may } \\
\text { initiate the group }\end{array}$ & $\begin{array}{l}\text { Price reduction and } \\
\text { increased quality; start } \\
\text { professionalizing purchas- } \\
\text { ing processes }\end{array}$ & $\begin{array}{l}\text { Total cost reduction; emphasis on efficiency } \\
\text { and maintenance; increase value for } \\
\text { supply chain }\end{array}$ & \\
\hline $\begin{array}{l}\text { Strategy and } \\
\text { activities }\end{array}$ & $\begin{array}{l}\text { Purchase generic commodities col- } \\
\text { laboratively; share information; } \\
\text { focus on tendering, negotiation, and } \\
\text { approved supplier lists }\end{array}$ & $\begin{array}{l}\text { Purchase more complex } \\
\text { commodities; focus on } \\
\text { tendering and contract- } \\
\text { ing, and cross functional } \\
\text { teams }\end{array}$ & $\begin{array}{l}\text { Offer more diversified commodities and } \\
\text { services; focus on vendor rating, systems } \\
\text { integration, outsourcing, and e-procure- } \\
\text { ment }\end{array}$ & \\
\hline Organization & $\begin{array}{l}\text { Decentralized; little planning and } \\
\text { coordination; informal communica- } \\
\text { tion and structure; role of purchasing } \\
\text { is clerical and reactive to needs of } \\
\text { others }\end{array}$ & $\begin{array}{l}\text { From decentralized to } \\
\text { centralized; membership } \\
\text { criteria; from informal } \\
\text { to formal; purchasing } \\
\text { becomes a strategic } \\
\text { facilitator }\end{array}$ & $\begin{array}{l}\text { Centralized; may be a stable private enter- } \\
\text { prise; multidisciplinary; possibly manda- } \\
\text { tory participation; formalization of rules; } \\
\text { purchasing supports and integrates with } \\
\text { members' strategies }\end{array}$ & \\
\hline $\begin{array}{l}\text { Resources and } \\
\text { support staff }\end{array}$ & $\begin{array}{l}\text { Members manage all aspects; members } \\
\text { are volunteers }\end{array}$ & $\begin{array}{l}\text { Group develops separate } \\
\text { resources }\end{array}$ & $\begin{array}{l}\text { E-catalogs and e-links with members; group } \\
\text { develops very competent resources }\end{array}$ & \\
\hline $\begin{array}{l}\text { Supplier relation- } \\
\text { ships }\end{array}$ & \multicolumn{2}{|c|}{$\begin{array}{l}\text { Bid competition; operational and tactical buying; multisupply; mul- } \\
\text { tirelationships }\end{array}$} & $\begin{array}{l}\text { Develop supplier partnerships; joint working } \\
\text { and drive innovation; network of fewer } \\
\text { key suppliers }\end{array}$ & \\
\hline
\end{tabular}

* Based on D'Aunno and Zuckerman 1987; Johnson 1999; Nollet and Beaulieu 2003.

To identify small-scale developments, we draw on the life-cycle model in table 1 and aim to add more detail by identifying smallscale developments that take place in the early life-cycle phases. For each dimension in table 1, we expect that after several small-scale developments, a purchasing group develops from one life-cycle phase to the next. In addition, we expect the dimensions to occur consistently across group members, so that purchasing groups develop on all dimensions more or less simultaneously.

\section{Method}

In this section, we first describe the case studies and discuss the link between our research question and the methodology. Next, we discuss the data collection and the research procedure.

\section{Data Sources}

We conducted three case studies, as multiple case studies allow for comparison and replication in multiple settings (Johnston, Leach, and Liu 1999). To build up a complete picture of the small-scale developments of a purchasing group, detailed data collection is necessary, and access is often a constraint. Therefore, we used convenience sampling in order to ensure in-depth case access (Miles and Huberman 1994). Hence, we chose to work with existing contacts to ensure that we gained a good understanding of the developments that take place in life-cycle phases. We have observed that governments in different countries are introducing policies on collaborative purchasing, so we chose to investigate groups from different countries to avoid limiting our potential findings to a particular country context or policy framework.

Based on prior knowledge through our contacts, the three cases were chosen because we were aware that they had been in existence for several years and that they represented relatively young, yet developed purchasing groups. This enabled us to look back over the early life-cycle phases. An advantage of studying the development of relatively young purchasing groups is that the first life-cycle phase of the groups took place only a couple of years ago. Therefore, a similar study of the creation of contemporary purchasing groups should not produce much different results (Miller and Friesen 1984). As we had ongoing relationships with the groups, we could also return to them if additional information was required to build a rich picture of their development. The three purchasing groups have been active for at least five years but fewer than 10 years. In the next three subsections, we describe the case studies in more detail.

Case study 1 The first case study investigates a purchasing group consisting of, at the time, almost 50 health care organizations in the United Kingdom. The members differ in size, among other things. The purchasing group is a separate organization, although not a separate legal entity. It started informally by building an organizational framework. A year later, the group started formally after securing funding from six members. The group services include strategic involvement with members and taking over the purchasing activities of some members. Members invest in the group against a promised return on investment, which is laid down in a service-level agreement. The main goals of the group are obtaining better leverage and compliance with contracts. Currently, the group is governed by a board of directors representing its members. It also has a chief executive officer who is responsible for day-to-day operations. Annually, performance targets are set, including the achievement of tangible savings for the members. The focus of the group lies in regional and local health purchasing, but attention is also paid to cross-government regional purchasing and the uptake of national contracts. 
Case study 2 The second case study investigates a purchasing group consisting of five Dutch municipalities. The members are all located in the same region, and the group is not a separate legal entity. By analyzing purchasing spending, the members found several opportunities for collaborative purchasing. Difficulties arise occasionally because of organizational differences, making it difficult for members to collaboratively improve the professional level of their purchasing functions and to find agreement on specifications. Still, all members evaluate the group as successful. Most collaborative projects lead to lower prices, improved process quality, and improved product quality. Currently, the group has a steering committee that coordinates the collaborative projects. During the steering committee meetings, the initiation and progress of collaborative projects is discussed. The group employs a part-time manager.

Case study 3 The third case study investigates a purchasing group consisting of 15 scientific-technical and biological-medical German research centers. The centers pursue long-term research goals on behalf of the state and society as autonomous scientific bodies. Some of the research centers operate sites all over Germany. Others operate locally, but all of them are already part of a registered association which loosely integrates strategic directions. The purchasing managers of the research centers participate in a management board, which meets twice a year to discuss topics concerning the purchasing function. After the liberalization of the energy markets, this board initiated the collaborative purchasing of electricity. The rotating leader of the board organizes and administers the collaborative purchase of electricity. The group, which is not a separate legal entity, carried out three tenders for electricity in several years' time. Difficulties arose occasionally because of differences in required contract terms. Nevertheless, cost reductions were achieved and duplication of efforts and activities was prevented. The group ended after the third tender because of problems with one of the suppliers during the supplier selection process for a new collaborative contract.

\section{Data Collection}

In order to understand how problematic factors interrelate in organizations, it is necessary to study the historical development of an organization by utilizing methods of longitudinal analysis (Miller and Friesen 1984; Smith, Carroll, and Ashford 1995). Therefore, we collected several sources of data over the complete timeline of the purchasing groups. The data sources include minutes, reports, business letters, administration data, and articles written about the groups over the complete timeline. We also carried out semistructured interviews with different stakeholders. These interviews were carried out to verify and complement the other data sources. We verified our interpretations of the interviews and our findings with the interview respondents. The data collection for each case study is summarized in table 2.
Denzin and Lincoln (1998) describe different forms of triangulation; our research involved (1) data triangulation by using different sources of information; (2) methodological triangulation by using interviews and document analysis, and (3) investigator triangulation, as all four researchers analyzed the summarized data of each case study and analyzed the codes and combined results of the case studies (this applies to, among other things, the coding mentioned in the procedure section, tables 3-7 in the results section, and the appendix, which describes tables 3-7 in more detail). There were some differences in interpretation between the researchers during the data analysis. We discussed these differences and went on refining the codes and combined results until the findings from the different researchers aligned. By using triangulation methods, we enhanced the reliability and internal validity of the study.

\section{Procedure}

Our research procedure was as follows. First, we created a detailed timeline for each purchasing group from their start to the time of collecting the data. We created the timelines by using procedures similar to those described by Miller and Friesen (1984), Dey (1993), Miles and Huberman (1994), Ariño and Torre (1998), and Beverland and Bretherton (2001). This means that every time a driver, condition, goal, problem, reaction, or achievement was mentioned in one of the data sources, we added this as a point to the timeline. We concentrated our analysis on interorganizational phenomena. For instance, we incorporated all problems that arise from the difficulty of coordinating activities of several different group members, each of which has its own goals and established routines (Montjoy and O'Toole 1978).

Second, we searched for patterns in the timelines of the three case studies by using procedures similar to those described by Miller and Friesen (1984) and Miles and Huberman (1994). We identified similarities and differences between the cases and coded all issues found. We used different codes for different types of issues. For example, we used codes such as "driver number one," "achievement number one," "achievement number two," and so on. For similar issues, we used the same codes. For example, we used the same code for all problems regarding the issue that the members of a purchasing group have different purchasing needs.

Third, we classified the codes by using the dimensions shown in table 1. For example, we classified the code for "flexible agreements with suppliers" as the dimension "supplier relationships."

Fourth, for each dimension, we placed all codes of the case studies in chronological order in one document. This document allowed us to position the codes by using the life-cycle phases shown in table 1 . The chronological order of the codes turned out to be predictable.

Table 2 Data Collection Summarized

\begin{tabular}{|c|c|c|c|}
\hline Description & Case study 1 & Case study 2 & Case study 3 \\
\hline Number of interviews & 9 & 4 & 3 \\
\hline $\begin{array}{l}\text { Period of time during which the data } \\
\text { was collected }\end{array}$ & 2000-2007 & 1998-2007 & 1998-2005 \\
\hline Sources of documentation & $\begin{array}{l}\text { All minutes, reports, business letters, } \\
\text { administration data, articles }\end{array}$ & $\begin{array}{l}\text { All minutes, reports, administration data, } \\
\text { articles }\end{array}$ & $\begin{array}{l}\text { All minutes, all tender records, adminis- } \\
\text { tration data }\end{array}$ \\
\hline Meetings attended & - & 31 , including 3 focus group meetings & - \\
\hline
\end{tabular}


It rarely happened that the order of the codes in one case was much different from the order in another case.

Based on the results of the analysis just described, we identified several small-scale developments for each dimension and for each life-cycle phase. Finally, we used the format of the purchasing development model of Monczka et al. (Axelsson, Rozemeijer, and Wynstra 2005; Leyenaar et al. 2005) to structure how we presented the small-scale developments. This means that we used similar sentence structures and similar sentence parts, such as "Like 2," as Monczka et al. did in their model. Tables 3-7 in the next section and the appendix show the results of this formatting exercise. As we only used the development model of Monczka et al. as a format, it did not influence the actual content of our results, but gave us a structure and format for the data.

By building the timelines, we integrated the different data sources. In addition, we reduced the size of the data set to three orderly timelines. The largest timeline (case study 2) consisted of 132 points, such as drivers or problems. The smallest timeline (case study 3) consisted of 75 points.

\section{Results}

In this section, we identify the small-scale developments that took place in the early life-cycle phases in the case studies. This means that for each dimension in table 1, we describe several achievements, problems, and possible reactions that may occur in the early life-cycle phases. The achievements, problems, and reactions are integrated in tables 3-7. In other words, the five tables summarize the small-scale developments of the purchasing groups analyzed on five dimensions (a more complete overview of the small-scale developments is shown in the appendix). In succession, we discuss these small-scale developments for each dimension.

\section{Member Relationships Dimension}

The summarized small-scale developments for the member relationships dimension are shown in table 3 (see appendix). The table shows that the purchasing groups were set up by members inexperienced in collaborative purchasing. The concept of collaborative purchasing seemed beneficial to them, but in order to gain collaborative benefits, the members first had to invest in the group. This resulted in some internal resistance. The members overcame this resistance by engaging with internal stakeholders-for instance, by assigning problem owners from relevant stakeholder groups. To resolve differences between the members, all case studies set flexible collaborative arrangements in place. Differences in experience and knowledge were resolved by bridging gaps through benchmarking or offering training. Note that differences in specifications and supplier preferences have an impact on both the dimension "activities" and the dimension "member relationships." To be able to cope with mutual differences, the members synchronized some differences (dimension "activities") and/or used flexible collaborative arrangements (dimension "member relationships").

In the second life-cycle phase, a higher level of trust between the members became present. Commitment between the members became more and more important as the groups carried out additional collaborative activities. As the group size became larger in case study 1, it became more difficult to manage the relationships between the members and to address all member concerns equitably. For case study 2, this was one of the reasons for expanding the group slowly.

\section{Goals Dimension}

Table 4 gives the small-scale developments for the goals dimension (see appendix). The table shows that the purchasing groups started with simple goals, such as reducing purchasing prices, reducing transaction costs, and sharing information. At the end of the first life-cycle phase, the goals of the individual organizations regarding the purchasing group were synchronized to a large extent.

In the second life-cycle phase, case studies 1 and 2 also started to professionalize purchasing processes that took place within the purchasing departments of the members. As the goals became more sophisticated and organization-wide, it became more important to clearly communicate the goals to all stakeholders. Overall, case studies 1 and 2 developed from an ad hoc and purchasing focus to a more general business and corporate focus.

\section{Strategy and Activities Dimension}

Table 5 shows the developments for the dimension that is related to establishing what to do together in a purchasing group (see appendix). The table shows that the purchasing groups started with an ad hoc approach by a small number of enthusiasts. As the members came from different starting points, synchronization of specifications, contracts, terms, and suppliers was necessary in all case studies. After the first quick wins were achieved, it became useful to carry out a basic spending analysis for identifying new potential collaborative projects. This approach was used in case studies 1 and 2. It turned out to be difficult to compare spending analyses of the individual organizations, as the systems of the members were not synchronized yet. For case study 3, questionnaires were used to find

Table 3 Small-Scale Developments for Establishing Member Relationships

\begin{tabular}{|c|c|}
\hline Life-cycle phase & Small-scale development \\
\hline \multirow{4}{*}{$\begin{array}{l}\text { Informal } \\
\text { coalition } \\
\text { emergence }\end{array}$} & 0 . No attention is paid to member relationships \\
\hline & $\begin{array}{l}\text { 1. Members not experienced in collaborating; no enforced col- } \\
\text { laboration; some internal resistance }\end{array}$ \\
\hline & $\begin{array}{l}\text { 2. Collaborative arrangements are made; group prevents moti- } \\
\text { vation problems and inequality }\end{array}$ \\
\hline & $\begin{array}{l}\text { 3. Like } 2 \text {, but group increases bonding; difficult to allocate } \\
\text { savings }\end{array}$ \\
\hline \multirow{3}{*}{$\begin{array}{c}\text { Formal col- } \\
\text { laborative } \\
\text { transition }\end{array}$} & 4. Like 3, but members know and trust each other well \\
\hline & 5. Like 4, but commitment is sustained at senior levels \\
\hline & $\begin{array}{l}\text { 6. Like 5, but difficult to manage many members; group is not } \\
\text { free of engagement anymore }\end{array}$ \\
\hline Maturity & $\begin{array}{l}\text { 7. Like } 6 \text {, but group becomes more capable in addressing } \\
\text { member concerns }\end{array}$ \\
\hline
\end{tabular}

Table 4 Small-Scale Developments for Establishing the Goals of the Group

\begin{tabular}{|c|c|}
\hline Life-cycle phase & Small-scale development \\
\hline \multirow{4}{*}{$\begin{array}{l}\text { Informal coali- } \\
\text { tion emer- } \\
\text { gence }\end{array}$} & 0. No clear goals \\
\hline & 1. Goals are general and oriented toward purchasing \\
\hline & 2. Like 1 , but goals are also set for specific projects \\
\hline & 3. Like 2 , but all members share similar collaborative goals \\
\hline \multirow{3}{*}{$\begin{array}{l}\text { Formal col- } \\
\text { laborative } \\
\text { transition }\end{array}$} & 4. Like 3 , but goals are compared to the final results \\
\hline & 5. Like 4, but goals are communicated to stakeholders \\
\hline & $\begin{array}{l}\text { 6. Like } 5 \text {, but it is also an goal to improve the purchasing proc- } \\
\text { esses of members }\end{array}$ \\
\hline Maturity & $\begin{array}{l}\text { 7. Like } 6 \text {, but goals are also oriented toward a strategic level, } \\
\text { contributing to general business concerns and priorities, } \\
\text { including full supply chains }\end{array}$ \\
\hline
\end{tabular}


Table 5 Small-Scale Developments for Establishing What to Do Together

\begin{tabular}{|c|c|}
\hline Life-cycle phase & Small-scale development \\
\hline \multirow{4}{*}{$\begin{array}{l}\text { Informal } \\
\text { coalition } \\
\text { emergence }\end{array}$} & 0. No structured decision making process \\
\hline & 1. Ad hoc approach; group purchases simple generic items \\
\hline & $\begin{array}{l}\text { 2. Quick win approach; projects are initiated by shared events; } \\
\text { members start synchronizing }\end{array}$ \\
\hline & $\begin{array}{l}\text { 3. Like } 2 \text {, but members compare basic spending analyses and } \\
\text { ask for legal advise before tenders }\end{array}$ \\
\hline \multirow{3}{*}{$\begin{array}{l}\text { Formal } \\
\text { collaborative } \\
\text { transition }\end{array}$} & $\begin{array}{l}\text { 4. Like 3, but members compare extensive spending analyses; } \\
\text { group purchases complex items }\end{array}$ \\
\hline & $\begin{array}{l}\text { 5. Like 4, but pros and cons of projects are communicated; } \\
\text { complex tenders lead to more differences }\end{array}$ \\
\hline & $\begin{array}{l}\text { 6. Like } 5 \text {, but members benchmark purchasing functions; } \\
\text { stakeholders are consulted before tenders }\end{array}$ \\
\hline Maturity & $\begin{array}{l}\text { 7. Like } 6 \text {, but group offers more diversified commodities and } \\
\text { services }\end{array}$ \\
\hline
\end{tabular}

new projects. This method lacked a thorough financial analysis, but there were no synchronization problems.

In the second life-cycle phase, the members of case studies 1 and 2 started conducting more extensive spending analyses. The members also carried out tenders for more complex items. Examples include the procurement of management consultancy services, care services, and information and communication technologies. To be able to purchase complex items as a group, more synchronization efforts were necessary for case study 1 . Case study 2 used a different approach and tendered more in lots to reduce the need for synchronization. Synchronization problems are seen as disadvantages of collaborative purchasing that are tolerated by the groups. It is accepted by the members that collaborative purchasing takes more time than individual purchasing because of synchronization.

\section{Organization Dimension}

Table 6 shows how the purchasing groups developed on the organization dimension (see appendix). The groups started by carrying out a feasibility study. For all case studies, common problems related to the autonomy of the members were resolved by setting up an informal voluntary group and by voluntary collaboration. In the group, decisions were made using consensus decision making. Furthermore, all groups defined and agreed on contract commitment, the evaluation of outcomes, and the communication and information provision. At the end of the first life-cycle phase, tasks were clearly divided among the members, which was a problematic issue in the beginning of this life-cycle phase.

In the second life-cycle phase, agreements were made to prevent midway cancellations by members. To prevent inconsistent or incomplete evaluations, the group in case study 1 created standardized evaluation procedures. The group in case study 2 sent more reminders regarding evaluations. Furthermore, in case studies 1 and 2, an important distinction was made between central (one member or an external party carries out the tasks for a tender) and coordinated purchasing (several members carry out the tasks in a coordinated manner).

\section{Resources and Support Staff Dimension}

Table 7 shows the developments for the group resources and support staff dimension (see appendix). To inform and keep the members up to date, the groups used different methods. The groups published simple newsletters, reports, records on progress, and/or a website.
Table 6 Small-Scale Developments for Establishing the Organizational Structure of the Group

\begin{tabular}{ll}
\hline Life-cycle phase & Small-scale development \\
\hline Informal & 0. No coordination between members \\
coalition & 1. A feasibility study is carried out and a group is set up; a \\
emergence & steering committee is set in place \\
& $\begin{array}{l}\text { 2. Like 1, but members may use trial periods for new items; } \\
\text { group uses consensus decision making }\end{array}$ \\
3. Like 2, but tasks are clearly divided and there are some \\
procedures; there is management support \\
collaborative & $\begin{array}{l}\text { 4. Like 3, but group becomes multidisciplinary and prevents } \\
\text { midway cancellations during tenders }\end{array}$ \\
& $\begin{array}{l}\text { 5. Like 4, but management decides whether centralized, de- } \\
\text { centralized, or coordinated purchasing is suitable }\end{array}$ \\
6. Like 5, but centralized purchasing is carried out by an exter- \\
nal party or by the group's personnel
\end{tabular}

Across the cases, it appears that some similar collaborative problems were hard to solve (e.g., "it is difficult to calculate savings"), and the purchasing groups are still searching for feasible solutions. At the end of the first life-cycle phase, supplier problems were handled on the group's behalf and not individually.

Next, the groups may start employing one or more group managers and/or assistants. For all groups, purchasing systems were set in place to manage the activities and contracts of the group. In the end of the second life-cycle phase, the groups also started measuring the performance of the group semiautomatically. For all case studies, problems related to favoritism were solved by establishing a sense of objectivity through leader rotation, a neutral office location, and/or a neutral party (e.g., "by turning the group into an independent third party organization").

\section{Supplier Relationships Dimension}

As the purchasing groups did not develop much on the dimension "supplier relationships," we omitted this dimension from our analysis. It is not unexpected that the groups did not develop much on this dimension, as the model in table 1 shows that there is no significant difference between groups in the first early life-cycle phase and groups in the second early life-cycle phase.

\section{Discussion}

Based on the results of the case studies, we observe that it does become more difficult at a small-scale level than at a large-scale level

Table 7 Small-Scale Developments for Establishing Resources and Support Staff

\begin{tabular}{|c|c|}
\hline Life-cycle phase & Small-scale development \\
\hline \multirow{4}{*}{$\begin{array}{l}\text { Informal } \\
\text { coalition } \\
\text { emergence }\end{array}$} & 0. No dedicated resources \\
\hline & $\begin{array}{l}\text { 1. The members start newsletters and records to inform each } \\
\text { other }\end{array}$ \\
\hline & $\begin{array}{l}\text { 2. Like 1, but group also reports about savings and plans; dif- } \\
\text { ficult to calculate and allocate savings }\end{array}$ \\
\hline & $\begin{array}{l}\text { 3. Like } 2 \text {, but group has its own website with information } \\
\text { about the collaborative activities }\end{array}$ \\
\hline \multirow{3}{*}{$\begin{array}{l}\text { Formal } \\
\text { collaborative } \\
\text { transition }\end{array}$} & $\begin{array}{l}\text { 4. Like } 3 \text {, but group employs one or more managers and/or } \\
\text { assistants }\end{array}$ \\
\hline & $\begin{array}{l}\text { 5. Like } 4 \text {, but a purchasing/contract management system/portal } \\
\text { is set in place }\end{array}$ \\
\hline & $\begin{array}{l}\text { 6. Like } 5 \text {, but group uses performance indicators to measure its } \\
\text { performance }\end{array}$ \\
\hline Maturity & $\begin{array}{l}\text { 7. Like } 6 \text {, but the group uses e-auctions and has e-catalogs and } \\
\text { e-links with its members }\end{array}$ \\
\hline
\end{tabular}


to predict the development of an individual purchasing group. Nevertheless, we observe that most of the small-scale problems occurring in purchasing groups follow a predictable path (see also tables 3-7 and the appendix). For each dimension, this confirms that the core theoretical assertion of the life-cycle models - that purchasing groups pass through predictable life-cycle phases-is also true on a small scale. Despite the fact that our findings are formulated at a small-scale level and the previous findings of D'Aunno and Zuckerman (1987), Johnson (1999), and Nollet and Beaulieu (2003) are formulated at a life-cycle phase level, our findings confirm most of the existing life-cycle phases. As the previous studies were carried out in health care and the education sector, and our study also included different sectors through studying health care organizations, municipalities, and research centers, it seems reasonable to believe that the previous findings and our findings hold lessons for public practice in general. Potential problems and decision-making points are elicited, which can determine the future development of relatively young purchasing groups.

Despite the fact that most of the small-scale problems follow a predictable path, the ways in which the purchasing groups deal with these problems may differ depending on the specific situation of the group. When comparing the cases, we found similarities in the type of problems and reactions to these problems, but, as shown in the results section, we also found different responses to similar problems. The similarities indicate that certain problems have similar "logical" responses, while the differences indicate that people can respond differently to the same problem given the specific situation of the group. It might well be that culture and industry differences also play a factor in the differences in responses. This is in line with contingency theory (e.g., Woodward 1958, 1965), which suggests that different organizational forms and responses are appropriate in different circumstances. The way in which responses affect the performance of a purchasing group requires further investigation.

It turns out that the dimensions of the existing life-cycle models of purchasing groups (see table 1) do not have to be cohesive. The existing theoretical assertion of life-cycle models suggests that groups have to develop all dimensions simultaneously, as young purchasing groups become older, larger, and more complex (based on Miller and Friesen 1984). Our results do not imply this, but state that this theoretical assertion is only true on a dimensional level. Depending on the form of a group, it might be that a group develops much on one dimension (e.g., it develops on one dimension to a mature life-cycle phase), yet not on another (e.g., on another dimension it remains in the earliest life-cycle phase). For instance, the third case study only involved the collaborative purchasing of electricity. For this reason, resources such as a contract management system were not necessary. Therefore, group showed almost no development on the dimension "resources and support staff." Because the group involved 15 members, the group had to pay more attention to the dimension "organization" than case study 2. Therefore, the group went through several small-scale developments on this dimension.

Finally, for some dimensions, small-scale developments can take place in a short period of time and can quickly develop to the next life-cycle phase. For other dimensions, more time seems necessary, and these dimensions may develop much slower. For instance, member relationships typically need time to evolve, corresponding with previous findings on collaboration between public sector organizations (Leach 2006). Usually, the members of young purchasing groups need some experience in collaborative purchasing and need to know and trust each other before complex tenders can be conducted.

\section{Limitations}

This study has some limitations, starting with the case studies selected. We conducted only three case studies of purchasing groups in the public sector. Because we studied a limited number of cases, we were able to research the case contexts in depth at a small-scale level. Still, our limited number of case studies will affect the generalizability of the findings, in particular when trying to match responses to specific problems and their applicability to the private sector. More case studies might reveal more problems and potentially more possible reactions to problems. In addition, the lengths of periods of analysis vary to some extent. Therefore, it is not possible to draw conclusions about rates of change (Miller and Friesen 1984). In our selection of cases, it is also difficult to compensate for survivor bias, as we only studied relatively successful groups. Further limitations concern the methodological approach and analysis adopted. We studied the evolution of the purchasing groups partly in retrospect. This may have affected the data and our findings, as people are selective and can be biased in what they remember. We tried to counter this as much as possible through triangulation of data (Miles and Huberman 1994). Finally, as our focus was on the development of the purchasing groups, we did not include a focus on industry- and/or countryspecific factors. We propose that future research should include this, as it could uncover additional or alternate insights into the development of purchasing groups.

\section{Managerial Implications}

Our research has implications for policy makers and practitioners. Policy makers need to be mindful that despite the introduction of collaborative purchasing policies in different countries, purchasing groups may founder in their implementation. More thought may need to be put into support for purchasing groups to maximize the chances of their success. This research identifies five dimensions that may contribute to success in early stages of collaboration in purchasing groups, which may have salience for practitioners about to embark on or in the early stages of collaborating on purchasing. These dimensions include "member relationships," "goals," "strategies and activities," "organization," and "resources and support staff."

If one wants to develop a purchasing group, then specific attention should be paid to the interorganizational management dimensions "strategy and activities" and "goals." Among other things, these dimensions concern the decision whether to collaborate and, if agreed between parties, it can support collaborative working as it specifies the direction of travel for a group. If a group does not develop in these dimensions, then it will most likely not get involved in the collaborative purchasing of complex or primary purchasing needs. Also, if conscious decisions regarding the dimensions "strategy and activities" and "goals" are not made and a purchasing group is set up in an inappropriate situation, this could affect the development of the group.

The tables in the appendix can practically assist purchasing groups in their development. The tables in the appendix provide detailed 
descriptions of small-scale developments of purchasing groups in early life-cycle phases. For each dimension, purchasing groups could determine the desired situation for the group, as well as assess where they currently see themselves as positioned on the various dimensions. If the current and desired situations differ and development is necessary, then the small-scale developments mentioned in the appendix can assist the group in reaching the desired situation step by step. This could help prevent groups from failing or dismantling, particularly in the early stages. The tables in the appendix could be modified into a formalized managerial tool to help groups develop. Furthermore, the problems and pitfalls of small-scale developments of groups in early life-cycle phases could be introduced in training for public sector procurers who are contemplating collaborative purchasing.

\section{Conclusion}

Our results draw on the experiences of three relatively young yet developed public sector purchasing groups. Although we conducted an exploratory study, the results provide a new small-scale perspective on collaborative purchasing. The results include solutions to collaborative purchasing problems and detailed descriptions of typical small-scale developments that take place in the early life-cycle phases in purchasing groups. The results contribute to the literature by providing a detailed life-cycle model for purchasing groups (see tables 3-7 and the appendix). The typical small-scale developments can help us better understand, learn from others, and enable the development of groups step by step, ultimately to improve their performance. This improved understanding can also help to build competence and trust and, if necessary, increase members' willingness to hand over responsibility and allow the life-cycle level change from a local informal network into a more distant and structured third party that takes over procurement tasks and activities.

We observe that most of the small-scale problems occurring in purchasing groups follow a predictable path, but the way in which the purchasing groups deal with these problems may differ depending on the specific situation of the purchasing group. We also show that in contrast to the existing life-cycle models for collaborative purchasing (see table 1), it turns out that not all dimensions of the life-cycle models are cohesive. This means that purchasing groups do not have to develop all dimensions simultaneously. Depending on the form of a group, it might be that a group can develop first on one dimension yet not on another.

\section{Implications for Further Research}

To further the understanding of collaborative purchasing in future research, more steps, problems, and possible solutions could be studied and added to the results in tables 3-7 and the appendix. More longitudinal studies could also help explore the small-scale developments of later life-cycle phases and assess the validity of

our findings in the early phases, as they could enable us to observe closely what happens at the time when problems and changes occur.

Future research could investigate industry- and/or country-specific factors and how they influence the developments of a purchasing group. For example, there could be a more in-depth investigation of small-scale developments in specific sectors such as health care, or as demonstrated in the collaborative purchase of specific goods and services such as electricity, or how the country policy context affects the development of groups. Such directions for further research could uncover additional or alternate insights into the development of groups.

The variation in responses to purchasing group developments could also be scrutinized in more depth, investigating the influence of variables such as the specific situation of the group, the personal attributes and attitudes of the practitioners, and the organizational cultures of the member organizations. In addition, the way in which purchasing group responses affect the performance of groups would be worthy of further research. This line of investigation would be particularly important for policy makers and practitioners who are keen to demonstrate the relationship between collaborative purchasing and organizational performance.

We observe that most of the small-scale problems occurring in purchasing groups follow a predictable path, but the way in which the purchasing groups deal with these problems may differ depending on the specific situation of the purchasing group.

Our research results show that how much purchasing groups develop on the dimensions can vary under different circumstances. ... This raises new and intriguing research questions related to which ideal combinations of dimension developments are desired under which circumstances to achieve successful collaboration.
Our research results show that how much purchasing groups develop on the dimensions can vary under different circumstances. As noted, purchasing groups do not have to develop the different dimensions simultaneously. This means that the theoretical assertion of the life-cycle models that groups pass through predictable life-cycle phases is only true on a dimensional level. On a higher general level, the theoretical assertion does not have to be true as the dimensions do not have to develop simultaneously. This raises new and intriguing research questions related to which ideal combinations of dimension developments are desired under which circumstances to achieve successful collaboration. Certain ideal combinations of dimension developments could be identified as new purchasing group types. Possible group types are:

- Large centralized purchasing groups. Such groups ideally have many members to obtain economies of scale. It is important to address the many member concerns equitably and sustain commitment of the members. The organization should be organized centrally, as it would cost too much time and effort to involve all members in the decision-making processes. As a result, the group should have very competent resources. This means that the dimensions "age and size," "member relationships," "organization," and "resources and support staff" should be mature. The other dimensions could be mature, but do not necessarily have to be so to be a successful purchasing group.

- Small coordinated purchasing groups with few members. Such groups ideally have few members to be able to learn from each other and carry out tasks collaboratively. As the group is 
Appendix: Detailed Small-Scale Development Descriptions of Purchasing Groups

Table A.1 Small-Scale Developments for Establishing Member Relationships

Life-cycle phase Small-scale developments for establishing member relationships

Informal coalition 0 . The members share similar ideologies, but do not pay attention to member relationships.

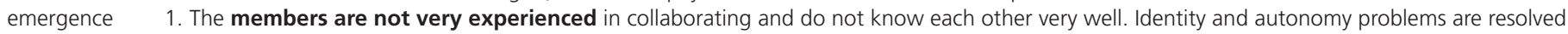
by not enforcing collaboration. Collaborative results are not immediately apparent and therefore, there may be some internal resistance.

2. Differences in needs are resolved by (flexible) collaborative arrangements with suppliers and members, such as a formal declaration of intent. It is made clear what all members expect and the arrangements are based on an understanding of member needs. To prevent motivation problems and inequality, rotation of tasks could be set in place.

3. Like 2, but the group increases bonding to improve the interpersonal relations between senior managers and purchasers of the members. This can be done by informal meetings. It turns out to be difficult to allocate gains, costs, and risks equitably among members.

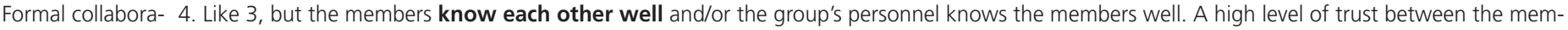
tive transition bers is present.

5. Like 4, but membership commitment is sustained at senior manager and purchaser level. The senior managers of the members and the managers of the group periodically meet to address the collaboration.

6. Like 5, but if the group size becomes larger, then it becomes more difficult to manage the many member relationships. Typically, the collaboration is not free of engagement anymore. The discussion may be started whether the organizational form needs drastic change.

Maturity 7. Like 6, but the group becomes more capable in addressing all member concerns equitably

Table A.2 Small-Scale Developments for Establishing the Goals of the Group

Life-cycle phase Small-scale developments for establishing the goals of the group

Informal coalition 0 . There are no clear goals for the purchasing group.

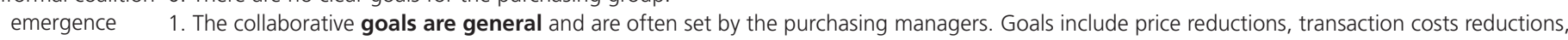
increased product quality, and sharing information. The goals are oriented toward purchasing

2. Like 1, but the collaborative goals are also set for specific projects. The goals are in line with the organizational goals of the members. General goals also include learning from each other and preventing duplication of efforts and activities. From now, the costs should be lower than the benefits.

3. Like 2, but the top managers of the members support the general collaborative goals. From now, all members share similar collaborative goals.

Formal collabora- 4. Like 3, but goals are compared to the final results and if necessary, corrective actions are taken.

tive transition 5. Like 4, but goals are also clearly communicated to all stakeholders.

6. Like 5 , but it is also an goal to improve the purchasing processes of the members. In addition, the members make priorities between goals.

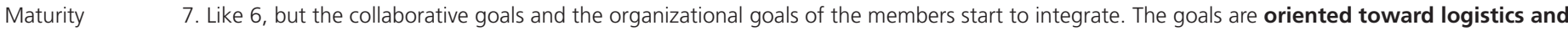
general business. The focus is on increased efficiency and reduced total costs of ownership.

Table A.3 Small-Scale Developments for Establishing What to Do Together

Life-cycle phase Small-scale developments for establishing what to do together

Informal coalition 0 . No structured decision making process exists for decisions concerning whether or not to collaborate.

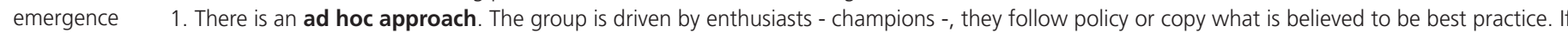
there is a shared purchasing need for simple generic items by chance, then the members tender collaboratively. It is not checked whether the members have sufficient mandate, internal support, resources, and knowledge to carry out the tenders. If the members lack specific knowledge, then consultancy services are used. The potential savings are rough estimates.

2. There is a quick win approach. From now, new projects are triggered by shared problems or shared needs. Specifications, suppliers, contract terms, and calendars are synchronized. There is a strong focus on buying secondary and standardized products with no emotional charge. The members share several purchasing tips and tricks during the meetings of the group.

3. Like 2, but the members compare basic quantitative spending analyses and benchmarks, giving insights in potential price and cost savings, similarities, differences, and potential problems. Spending analyses are difficult to compare as the systems of the members are not synchronized. It is difficult to find lucrative collaborative areas. A legal adviser is consulted before tenders are carried out to prevent transparency and juridical issues.

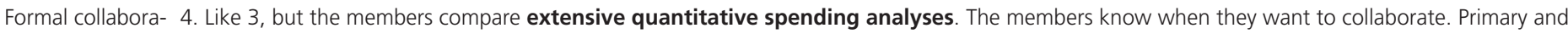
tive transition future purchasing needs are considered for the collaborative purchasing of simple and complex items. Mutual differences are confronted rather than ignored. So, more efforts are necessary for synchronization of purchasing procedures, plans, common procurement vocabulary codes, and purchasing conditions. Sometimes, the group tenders in lots or does not synchronize everything. When tendering in lots and/or using the concept of multiple sourcing, the focus is not on lower purchasing prices. In this case, collaborative goals are reducing transaction costs, sharing knowledge, and pooling resources.

5. Like 4, but the pros and cons of new projects are clearly calculated and communicated to each other. Complex tenders lead to more differences in needs. The commercial focus may increase.

6. Like 5, but the members compare quantitative and qualitative spending analyses and benchmark their complete purchasing functions to find more collaborating and learning opportunities. If the group is relatively small, then purchasing systems and supporting services are synchronized. All main stakeholders are consulted before complex tenders. Purchasing policies and supporting services are also synchronized

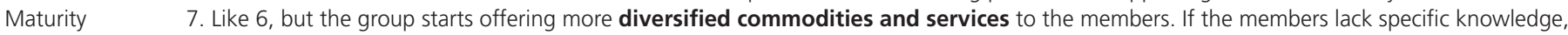
then workshops, education, and training sessions are offered by the group. This way, the purchasing competences of the members are further developed.

relatively small, it is not very difficult to address the differences in the members' needs adequately. The organizations should have a coordinated organization and all members can influence the decision-making processes. The members should have compe- tent recourses, but the group does not necessarily have to have such resources. The group should focus on total cost reduction, as goals such as price reduction can be better obtained by large groups. This means that the dimensions "age and size" and 
Table A.4 Small-Scale Developments for Establishing the Organizational Structure of the Group

\begin{tabular}{|c|c|}
\hline Life-cy & Small-scale developments for establishing the organizational structure of the group \\
\hline $\begin{array}{l}\text { nformal coalition } \\
\text { emergence }\end{array}$ & $\begin{array}{l}\text { 0. There is no coordination between the members. } \\
\text { 1. Extra member resources are made available to carry out a feasibility study and set up a group. The members can sign requirements of confiden- } \\
\text { tiality. For groups with many members or activities, a steering committee is set in place. The purchasing tasks are carried out by project groups. } \\
\text { There is a direct link between the steering committee and the project groups. } \\
\text { 2. Like 1, but the members may use trial periods for new items in case they cope with change resistance. They may also get alongside individuals } \\
\text { and tailor services to get support and people collaborating. The group uses consensus decision making. The members have made agreements } \\
\text { about when and how to inform each other about past (expiry dates), current, and future projects. } \\
\text { 3. Like 2, but the tasks are clearly divided and there are some collaborative procedures. Each contract has a contract manager to obtain contract } \\
\text { compliance and to keep the contracts up-to-date. Top management support is guaranteed by management sponsors. The members think about } \\
\text { whether or not others may join. }\end{array}$ \\
\hline $\begin{array}{l}\text { Formal collabora- } \\
\text { tive transition }\end{array}$ & $\begin{array}{l}\text { 4. Like 3, but the group becomes more multidisciplinary. The group makes clear agreements about how to communicate with each other. There } \\
\text { are clear procedures about how to obtain necessary information from the members for new joint tenders and there are membership criteria. The } \\
\text { group has exit moments during collaborative tenders and binding contracts are considered to prevent midway cancellations by members. To } \\
\text { prevent incomplete or inconsistent project evaluations, reminders are sent and evaluations are standardized and reported. } \\
\text { 5. Like 4, but the group kicks off new complex projects with all key persons as these projects have multiple stakeholders. Problems are proactively } \\
\text { dealt with. Top management decides whether centralized (one member carries out the tasks) or coordinated purchasing (several members } \\
\text { carry out the tasks) is suitable. } \\
\text { 6. Like 5, but centralized purchasing is carried out by an external party or by the group's personnel. This party or the group has specific expertise. } \\
\text { "Central" contracts have mandatory participation clauses. }\end{array}$ \\
\hline Maturity & $\begin{array}{l}\text { 7. Like 6, but the group has a stable structure and may become a private enterprise. The group's personnel is multidisciplinary. For "coordinated" } \\
\text { items, the contracts may also have mandatory participation clauses. }\end{array}$ \\
\hline
\end{tabular}

Table A.5 Small-Scale Developments for Establishing Resources and Support Staff

\begin{tabular}{|c|c|}
\hline Life-cycle phase & Small-scale developments for establishing resources and support staff \\
\hline \multirow{4}{*}{$\begin{array}{l}\text { Informal coalition } \\
\text { emergence }\end{array}$} & 0. The group has no dedicated resources. \\
\hline & $\begin{array}{l}\text { 1. The members start newsletters and records to inform each other about the progress of the group. The group has its own name. The available } \\
\text { resources are often limited. }\end{array}$ \\
\hline & 2. Like 1 , but the group also reports about savings and plans. It is difficult to calculate the collaborative savings. \\
\hline & $\begin{array}{l}\text { 3. Like 2, but the group has its own website with information about the members, the group, the collaborative activities, and special details. Sup- } \\
\text { plier problems are handled on the group's behalf. }\end{array}$ \\
\hline \multirow{3}{*}{$\begin{array}{l}\text { Formal collabora- } \\
\text { tive transition }\end{array}$} & 4. Like 3, but the group employs one or more managers and/or assistants. The costs are shared. \\
\hline & $\begin{array}{l}\text { 5. Like } 4 \text {, but a purchasing/contract management system/portal is set in place to manage the activities and contracts of the group. All members } \\
\text { have access to the contracts in which they participate. }\end{array}$ \\
\hline & $\begin{array}{l}\text { 6. Like } 5 \text {, but the group uses performance indicators to automatically measure the performance of collaborative activities and contract compli- } \\
\text { ance. The administration and management team of the purchasing group may become independent and is neutral. }\end{array}$ \\
\hline Maturity & $\begin{array}{l}\text { 7. Like } 6 \text {, but the group uses e-auctions and has e-catalogs and e-links with its members. It has very competent resources regarding conducting } \\
\text { tenders and collaborative activities. }\end{array}$ \\
\hline
\end{tabular}

"organization" should be in the early life-cycle phases. The dimensions "goals" and "strategy and activities" should be mature.

Future research is necessary to find out what combinations of characteristics lead to organizational effectiveness of different group types under which circumstances. Such research could show that groups with some mature characteristics in combination with some infantile characteristics could still be successful groups.

\section{Acknowledgments}

We thank Kristine Langenbucher from Bundeswehr University Munich, Jan Telgen from the University of Twente, and the referees of the Dutch Purchasing Research Workshop for their useful comments and contributions to the paper. We acknowledge partial financial support from the Netherlands Organization for Scientific Research, the Dutch Association for Purchasing Management, and the National Health Service Purchasing and Supply Agency (the agency does not exist anymore and has been merged with other health departments, such as the Department of Health and Buying Solutions).

\section{References}

Arińo, Africa, and José de la Torre. 1998. Learning from Failure: Towards an Evolutionary Model of Collaborative Ventures. Organization Science 9(3): 306-25.

Australia. Department of Finance and Deregulation. 2008. Cooperative Agency Procurement. Canberra: Australian Government Department of Finance and Deregulation.
Axelsson, Björn, Frank Rozemeijer, and Finn Wynstra, eds. 2005. Developing Sourcing Capabilities. Chichester, UK: Wiley.

Bakker, Elmer, Helen Walker, Fredo Schotanus, and Christine Harland. 2008. Choosing an Organisational Form: The Case of Collaborative Procurement Initiatives. International Journal of Procurement Management 1(3): 297-317.

Beverland, Mike, and Philip Bretherton. 2001. The Uncertain Search for Opportunities: Determinants of Strategic Alliances. Qualitative Market Research: An International Journal 4(2): 88-99.

Bevir, Mark, and David O'Brien. 2001. New Labour and the Public Sector in Britain. Public Administration Review 61(5): 535-47.

Communities and Local Government. 2008. The National Procurement Strategy for Local Government—Final Report: Towards Public Service Transformation. http://www.supply2.gov.uk/pdfs/national_procurement_strategy.pdf [accessed December 15, 2010].

D’Aunno, Thomas A., and Howard S. Zuckerman. 1987. A Life-Cycle Model of Organizational Federations: The Case of Hospitals. Academy of Management Review 12(3): 534-45.

Denzin, Norman K., and Yvonna S. Lincoln, eds. 1998. The Landscape of Qualitative Research. Thousand Oaks, CA: Sage Publications.

Dey, Ian. 1993. Qualitative Data Analysis for Social Scientists. London: Routledge.

Greiner, Larry E. 1972. Evolution and Revolution as organizations grow. Harvard Business Review, 50(4): 37-46.

Johnson, P. Fraser. 1999. The Pattern of Evolution in Public Sector Purchasing Consortia. International Journal of Logistics: Research and Applications 2(1): 57-73. 
Johnston, Wesley J., Mark P. Leach, and Annie H. Liu. 1999. Theory Testing Using Case Studies in Business-to-Business Research. Industrial Marketing Management 28(3): 201-13.

Leach, William D. 2006. Collaborative Public Management and Democracy: Evidence from Western Watershed Partnerships. Public Administration Review 66(1): 100-110. Leyenaar, P., A. Schepper, H. de Visser, G. Kruijt and N. van Barschot. 2005. Purchasing Excellence Publiek [in Dutch]. Zoetermeer: NEVI.

Miles, Matthew B., and A. Michael Huberman. 1994. Qualitative Data Analysis: An Expanded Sourcebook. Thousand Oaks, CA: Sage Publications.

Miller, Danny, and Peter H. Friesen. 1984. A Longitudinal Study of the Corporate Life Cycle. Management Science 30(10): 1161-83.

Mintzberg, Henry. 1979. The Structuring of Organizations: A Synthesis of the Research. Englewood Cliffs, NJ: Prentice Hall.

. 1983. Structure in Fives: Designing Effective Organizations. Englewood Cliffs, NJ: Prentice Hall.

Monczka, Robert, Robert Trent, and Robert Handfield. 2005. Purchasing and Supply Chain Management. 3rd ed. Cincinnati, OH: South-Western.

Montjoy, Robert S., and Laurence J. O’Toole, Jr. 1979. Toward a Theory of Policy Implementation: An Organizational Perspective. Public Administration Review 39(5): 465-76.

National Association of State Procurement Officials (NASPO). 2006. Strength in Numbers: An Introduction to Cooperative Procurements. Lexington, KY: NASPO.

National Audit Office (NAO) and Audit Commission. 2010. A Review of Collaborative Procurement across the Public Sector. http://www.nao.org.uk/idoc. ashx?docId=fd6e225c-e987-4692-aa5f-72ef5f0df510\&version=-1 [accessed December 15, 2010].

Nollet, Jean, and Martin Beaulieu. 2003. The Development of Group Purchasing: An Empirical Study in the Healthcare Sector. Journal of Purchasing and Supply Management 9(1): 3-10.

2005. Should an Organisation Join a Purchasing Group? Supply Chain Management: An International Journal 10(1): 11-17.

PIANOo. 2007. Collaborative Purchasing. The Hague: PIANOo.

Schotanus, Fredo. 2007. Horizontal Cooperative Purchasing. Enschede, Netherlands: University of Twente.

Schotanus, Fredo, and Jan Telgen. 2007. Developing a Typology of Organisational Forms of Cooperative Purchasing. Journal of Purchasing and Supply Management 13(1): 53-68.

Smith, Ken G., Stephen J. Carroll, and Susan J. Ashford. 1995. Intra- and Interorganizational Cooperation: Toward a Research Agenda. Academy of Management Journal 38(1): 7-23.

Thompson, Grahame, Jennifer Frances, Rosalind Levacic, and Jeremy C. Mitchell, eds. 1991. Markets, Hierarchies and Networks: The Coordination of Social Life. London: Sage Publications.

United Kingdom. Her Majesty's Treasury. 2007. Transforming Government Procurement. London: Her Majesty's Treasury.

Woodward, Joan. 1958. Management and Technology. London: Her Majesty's Stationery Office.

1965. Industrial Organization: Theory and Practice. London: Oxford University Press.

NEXT UP ...

\title{
May/June 2011 issue of $P A R$
}

\section{The Changing Concept of a Federal Executive Budget: A Senior Junior Exchange}

A Symposium on Performance-Based Budgeting

Recent Trends in Public Sector Technological Innovations

\author{
A Public Document Review \\ Theory to Practice \\ Book Reviews
}

... and MORE! 